\title{
ASSESSING SOME FACTORS INFLUENCE QUALITY OF ACCOUNTING INFORMATION SYSTEM - IN VIETNAM
}

\author{
LUONG DUC THUAN \\ University of Economics Ho Chi Minh City, Vietnam \\ thuanluongktkt@ueh.edu.vn
}

\begin{abstract}
The study was conducted to examine the role of user involvement accounting information system, external expert and organizational structure factors for the quality of accounting information systems in enterprises in Ho Chi Minh City. Research samples of 175 people that working in accounting positions in different types of company. Research data were collected primarily through questionnaire survey (April, 2018 - July, 2018) and then it is used to analyze descriptive statistics and perform hypothesis testing tests through a linear regression analysis with the support of SPSS software. The result shows that the quality of the accounting information system is influenced by user involvement accounting information system and organizational structure factors with the level of impact is similar.

Keywords. User Involvement Accounting Information System, External Expert, Organizational Structure, Quality of Accounting Information System.
\end{abstract}

\section{INTRODUCTION}

In the current context, information technology has strong influence in all aspects of life, economy and society, besides the opportunities from globalization, Vietnam also has to face with many challenges, difficulties, there are difficult challenges related to the application of information technology to serve the development of enterprises. The development of enterprises is one of the strong impacts on the development of the AIS along with factors influencing the operation of the AIS such as requirements on the control and management of administrators, legislation in the field of accounting and the development of information technology.

In a competitive environment, businesses are exposed to a variety of factors that influence the effectiveness and effeciency of the AIS in implementing the system's functions and impact the quality of accounting information. According to many published studies, the quality of accounting information derives from the implementation of a quality of AIS (Sacer et al, 2006), so quality of AIS will generate good and useful accounting information and that is also the most important function of the AIS. By implementing the functions of AIS, it will help the company achieve its business objectives and help improve and enhance the efficiency and effectiveness of operations (Soudani, 2012), support for activities including the decision-making process of the manager (Gelinas et al, 2011). In addition, a quality of AIS and the effectiveness of internal controls also have a significant impact on the quality of financial statement, the effectiveness of AIS can lead to better decision-making by managers, the internal control system is more effective, improving the quality of financial statement and make a good condition for processing financial transactions (Sajady et al, 2008).

As such, it is possible to see a particularly important role of AIS in enterprises in Vietnam. This shows the necessity and appropriateness in the study of the quality of AIS, as well as the need to identify the key factors affecting the quality of AIS in accordance with the characteristics of the accounting system as well as the business transformation environment is very diverse and developing as Vietnam nowsday.

Therefore, this study was conducted to provide more empirical evidence of factors, namely user involvement, external expert and organizational structure that influences the quality of AIS in Vietnamese 
enterprises. To achieve this goal, the author based analysis of previous studies, combining quantitative methods through the survey of 175 agents working in different enterprises.

\section{LITERATURE REVIEW AND RESEARCH MODEL}

\subsection{User involvement accounting information system}

User involvement AIS is behavior and user activity that occurs during system development, for example, as the leader of the project team, responsible for the overall success of the system, and is responsible for the selection of hardware or software, cost estimation, capital requirements (Hartwick \& Barki 1994). Skills and knowledge of the participant use systems demonstrate compliance with the usage process, the level of proficiency and skill in system operation, and how to exploit information from the system.

The user AIS, in which accountants play an extremely important role in the system development cycle. From the view of the user, the accountants understand their own information needs, thereby assisting in identifying the system requirements for system development. As a member of the system development team, accountants have a role to join at the beginning of designing control components, monitor and test these controls for the system, which helps increase efficiency and minimize of system development costs. The involvement of system users in the development of information system is considered as an important mechanism to improve the quality of system and ensure the successful implementation of information system. There are many research results indicating that user involvement will enhance system use and user satisfaction with the system, in addition to the user satisfaction that will lead to use the system more (Baroudi et al, 1986). User involvement refers to the behavior and activities that users perform during system development from the planning, development to implementation phases. According to Susanto (2013), some important reasons for user involvement in the design and development of information systems: the need of users, knowledge and working conditions, dissatisfaction with information, users feel threatened, enhance democracy.

\subsection{Quality of Accounting Information System}

The views on the quality of AIS are mainly based on the viewpoint of the quality of the information system that has been implemented in prior studies and is analyzed from the quality viewpoint of the successful DeLone \& McLean model. Specific:

- According to DeLone \& McLean, 2003; Seddon, 1997, the quality of system is associated with success, and they use information system quality scales in line with the developed model including: ease of use, system functionality, reliability, flexibility, data quality, integration and importance. The quality of the information system involves measuring the output information of the actual system and are the desired characteristics of the system including: usability, availability, reliability, response time and meet demand. In the study by Peter et al (2008) on measuring the success of information systems related to modeling, dimensions, measuring scale and relationships, the authors claim that the system quality represents the desire characteristics such as ease of use, flexibility, reliability, ease-of-use, sophistication, and system response time. At the same time, in this study, the author uses the system quality scale of Sedera et al (2004), which includes nine observed variables to measure the quality of information system.

On the basis of the concept of quality of information system, there are many opinions of many authors about the quality of AIS, because in terms of the relationship of nature, the AIS is also information system and AIS has the characteristics of a information system. Specific:

- The quality of accounting information comes from the implementation of a quality of AIS. The quality of AIS is the integration of the quality of hardware, software, people, technology networks, databases, quality of work and user satisfaction (Sacer et al, 2006). Some authors have described the quality of the information system through: effectiveness, usefulness, efficiency, user satisfaction. The effectiveness of AIS is the evaluation of the successful AIS to meet 
established objectives, and one of the key objectives of the AIS is to provide accounting information for the decision-making process of the manager and the related parties.

- The effectiveness of AIS is to measure the success of the AIS to meet established objectives, or the satisfaction of the user (Stair \& Reynolds, 2010). According to him, the quality of AIS is often flexibility, effectively, accessibility and timely.0

\subsection{Organizational structure}

Organizational structure is the arrangement of organizational units in the organization. Organizational structure shows the division of labor and shows how different functions or activities combine to achieve established goals (Robbins, 2009; Jones \& Jones, 2010). At the same time, the organizational structure is the formal pattern in which tasks are divided and coordinated, organizational structure reflects the division of responsibilities, authority, and accountability in the organization. According to Greenberg (2011), organizational structure is a formal structure between individuals and groups of employees with the assignment of responsibilities, responsibilities and authority in the organization. One way to understand organizational structure is look at the organization chart, the organizational structure that provides the framework in which the activities of the enterprise are planned, implemented, control and monitor activities. Each enterprise has an organizational structure that suits its needs and business characteristics, so there is no common pattern; the organizational structure depends on the size and nature of the business. However, organizational structure of the business must help enterprises implement the strategy that is planned to achieve the goals through the role and function of AIS.

\subsection{External expert}

They are capable of analyzing existing systems, designing new systems and programming computeraided applications. Systems analysts can be internal and external to the business, as well as programmers, accountants, auditors, consultants, and accountants. They have extensive knowledge and experience related to the organization of accounting systems, the organization of control systems and the application of information technology in business management. For the development of large-scale accounting systems or the strong application of information technology, there is no lack of participation of this component. The mission of an analyst, system consultant is to study current systems, design new systems, develop and deliver technical specifications to programmers.

External experts refer to the extent to which external mediating entities such as vendors and consultants provide knowledge, training, maintenance, and technical support to the organization. For the purposes of this study, suppliers and consultants were classified as external specialists because of according to Sedera et al (2004), investigating the effect of management knowledge on ERP success , reported that these entities have an impact on the ERP system. Vendors and consultants are important role for ERP systems because organizations often lack expertise and staff to implement such systems (Attewell, 1992; Markus \& Tanis, 2000, Davenport, 2000). According to Markus \& Tanis (2000) and Wang \& Chen (2006), competent ERP vendors (such as external expert) not only train their clients during system implementation but also have many experience used in system maintenance and guidance. In the ERP system, organizations not only expect knowledge to be transferred and supported but also to their collaborative, reliable and valuable partners (Markus \& Tanis, 2000).

\subsection{Research model and Hypothesis}

The research model is based on the assumption that user involvement AIS, external expert and organizational structure have a direct impact on the quality of AIS (Figure 1). 


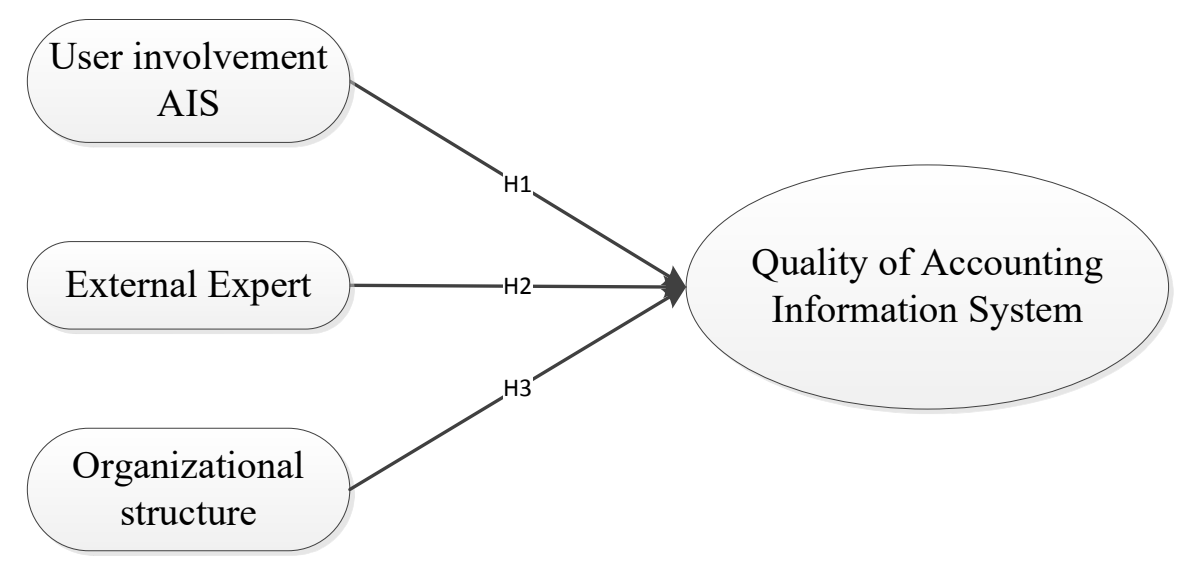

Figure 1. Research model

Participants using AIS can directly participate in decisions that may affect them, information systems need to be developed to meet the uer of needs. The success of the system has three components: the quality of the system, the benefits of the system and the user satisfaction. In system development, participation is a factor that must be considered to ensure user satisfaction to support the success of the system. The results of the study were presented by McKeen et al (1994) and Abelein \& Paech (2015) found that user involvement is an effective variable that determines user satisfaction, the success and quality of the information system, with the above arguments, the study assumes that:

\section{H1: The user involvement AIS has a positive impact on the quality of AIS.}

Although it is clear that external expertise is important to organizations when developing or applying new technologies (Attewell, 1992; Thong et al, 1996). Although most studies in information system theory, including Thong et al (1996), have shown that when the level of external expertise is high, the level of success of IT systems tend to be high. In relation to the ERP system, Sedera et al (2004) found that external expertise was closely related to the ERP success, which was confirmed by Wang \& Chen (2006). In general, the impact of the ERP system on individuals, member units and the whole organization is evaluated as positive when the suppliers, consultants have good qualities, prestige and cooperation (Gefen, 2004). In contrary, organizations and members of the organization may not be able to obtain the necessary support when external experts are of low quality. Therefore, the benefits from the system can be affected. Thus, this hypothesis is:

\section{H2: The external expert has a positive impact on the quality of AIS.}

A good organizational structure is showed through the specificity, clarity and completeness of functions, rights and obligations of each employee, each part of the company, and good organizational structure will assure for effective control procedures. When managers develop or change an organizational structure, they are involved in organizational design. According to Robbins \& Coulter (2009), the aspects and elements of organizational structure include: job specialization, the division of work activities into specific work tasks; scope of control is the number of employees that a manager can manage effectively and effectively; the chain of commands is the flow of authority from the top to the bottom of the hierarchy and is clearly assigned at the managers level; formalization, how this relates to the standard of organization's work and the level of performance of employees by conduct guided by procedures and rules; authorization (concentration and dispersion), centralization is the extent to which decisions are made at the high level, on the other hand the dispersion indicates that employees at the lower levels of supply more input data or make more current decisions.

Organizational structure is the main issue to be considered for the preparation of the AIS. The AIS is influenced by the organizational structure and organizational structure influences the AIS. Some studies 
in the world on the influence of organizational structure on the quality of AIS as studied by Rapina (2014); Anggadini (2013); Nusa (2015); Carolina (2014) shows that the organizational structure has a direct impact on the quality of AIS, therefore, the study assumes that:

H3: Organizational structure has a positive impact on the quality of AIS.

\section{RESEARCH METHODOLOGY}

\subsection{Research design}

The author uses the quantitative method to test hypotheses. The study was conducted by sending questionnaires to individuals working in companies, mainly in HCM city, regardless of size of enterprise, location of operation, type of enterprise and form of ownership. In particular, the main object surveyed in that business is the person in charge of accounting work or the accountant directly using AIS in the enterprise. Survey was conducted from April to July, 2018.

The content of the quantitative study was a questionnaire with the main content being scales related to measuring the management commitment factor according to Susanto (2013), scale of 7 observed variables (UIN1 to UIN5), the external expert variable is used of Davenport (2000) and Ifinedo \& Sundberg (2012) consists of 5 observed variables (EXP1 to EXP5), 5 observed variables of organizational structure (OST1 to OST5), used of Robbins \& Coulter (2009). The scale of quality of AIS by Gable et al (2003) and Sedera et al (2004) consisted of seven observed variables (ASQ1 to ASQ7). These observed variables were measured using a 5-point Likert scale (1: strongly disagree; 5: highly agree).

\subsection{Statistics describe the research pattern and data analysis method}

Information about the sample: A sample of 175 surveyed individuals working in a variety of businesses, including 71 limited liability companies (40.6\%), 60 joint stock companies (34.3\%), 20 private enterprises (accounting for 11.4\%), the remaining 24 enterprises, including state-owned enterprises and joint-venture enterprises $(13.7 \%)$ ). Regarding business activities of enterprises, the author classifies 6 types, the first one is financial investment accounting for $29.8 \%$, and the second is the trade and services with $25.8 \%$, followed by construction (21.5\%), manufacturing (15.2\%) and education and training and others at a rate of $7.8 \%$ ). The size of enterprises in the sample also varies, focusing mainly on medium and large enterprises with a total of 108 enterprises (61.8\%), followed by small enterprises $28 \%$ corresponding to 49 enterprises, followed by micro enterprises with 18 enterprises (rate of 10.3\%). Regarding the application of IT in accounting work, the largest number is application accounting software with 120 enterprises (accounting for 68.6\%), followed by is use Excel in accounting with 28 enterprises (16\%) and finally ERP software (15.4\%) corresponding to 27 enterprises using ERP software.

The sample size $(n=175)$ was evaluated by the Cronbach's Alpha coefficient, total correlation coefficient and EFA with criteria: Cronbach's Alpha coefficient greater than 0.6 (Hair et al, 2006), the total variable correlation coefficient is greater than 0.3 (Nunnally \& Bernstein, 1994), the KMO coefficient is greater than 0.5, Bartlett's test has P-value $<0.05$, explanation variance greater than $50 \%$. Research hypotheses were tested by multiple linear regressions, assessment and considered the effects of independent variables on dependent variable.

\section{RESULT AND DISCUSSION}

\subsection{Result of assess scales}

After complete data collection and input into SPSS 22 software, the author performs a scale measurement using the Cronbach Alpha coefficient to eliminate unreliable variables or trash variables in the scale. After eliminating the variables with a corrected item total correlation coefficient of less than 0.3 , the concepts of internal consistency, cronbach Alpha $>0.6$.

The results of Cronbach Alpha coefficient analysis in Table 1 (Source: Author calculates) 
Table 1. The results of Cronbach Alpha coefficient analysis

\begin{tabular}{|l|l|l|}
\hline Variables & Cronbach's Alpha & Result of eliminate variable \\
\hline User involvement AIS & 0.734 & No \\
\hline External expert & 0.845 & No \\
\hline Organizational structure & 0.761 & No \\
\hline Quality of AIS & 0.835 & No \\
\hline
\end{tabular}

The results of factor analysis for independent variables show that the KMO $=0.847$ satisfies the condition $>0.5$ and $<1$, so the factor analysis is consistent with the sample data. The results show that 3 factors were extracted with the total variance explained by three factors greater than $50 \%(55.936 \%)$, the weight factor was greater than 0.5 .

Table 2. The results of factor analysis

\begin{tabular}{|l|r|r|r|}
\hline & & & \\
& & & \\
& & & \\
Observed & Factors & \\
Variables & External expert & User involvement AIS & Organizational structure \\
\hline EXP3 & .787 & & \\
EXP5 & .765 & & \\
EXP4 & .752 & & \\
EXP2 & .725 & & \\
EXP1 & .683 & .747 & \\
UIN2 & & .697 & .821 \\
UIN1 & & .621 & .782 \\
UIN4 & & .501 & .582 \\
UIN5 & & & .492 \\
UIN3 & & & \\
OST2 & & & \\
OST1 & & & \\
OST3 & & & \\
OST5 & & & \\
OST4 & & & \\
\hline
\end{tabular}

The results of factor analysis for the quality of AIS showed that the KMO $=0.847>0.5$ and $<1$, the total variance explained was $50.64 \%$ ( $>50 \%$ ), observation variables do not change, so factor analysis is consistent with sample data. 
Table 3. The results of factor analysis for ASQ

\begin{tabular}{|l|c|}
\hline & \multicolumn{2}{|c|}{ Factor } \\
\cline { 2 - 3 } Observed variables & ASQ \\
\hline ASQ7 & \\
ASQ4 & .783 \\
ASQ2 & .771 \\
ASQ3 & .737 \\
ASQ6 & .730 \\
ASQ5 & \\
ASQ1 & .682 \\
\end{tabular}

\subsection{Result of analysis multiple linear regression}

From the results of the exploratory factor analysis, linear regression analysis was performed to determine the linear relationship between the independent variables (organizational commitment and organizational structure) and the quality of AIS. The regression model has the following form:

$Y=\beta 0+\beta 1 X 1+\beta 2 X 2+\beta 3 X 3+e$

Y: Quality of AIS (ASQ)

X1: User involvement AIS (UIN)

X2: External expert (EXP)

X3: Organizational structure (OST)

The Pearson correlation coefficient shows correlation between independent variables and dependent variable as well as between independent variables, including the correlation between independent and dependent variable with ( $\mathrm{p}$-value $<0.05$ ).

Table 4. Pearson correlation coefficient

\begin{tabular}{|c|c|c|c|c|}
\hline & $\begin{array}{c}\text { User } \\
\text { involvement } \\
\text { AIS } \\
\end{array}$ & $\begin{array}{c}\text { External } \\
\text { expert }\end{array}$ & $\begin{array}{l}\text { Organizational } \\
\text { structure }\end{array}$ & Quality of AIS \\
\hline User involvement AIS & 1 & $.488^{* *}$ & $.570 * *$ & $.505 * *$ \\
\hline External expert & & 1 & $.503 * *$ & $.388 * *$ \\
\hline Organizational structure & & & 1 & $.517 * *$ \\
\hline Quality of AIS & & & & 1 \\
\hline
\end{tabular}

Results of multiple linear regression analysis between independent variables and dependent variable are presented in Table 4. Correlation coefficient $\mathrm{R}^{2}=0.339$, $\mathrm{p}$-value $<0.05$ showed that $33.9 \%$ the variability of the dependent variable is explained by independent variables. There are two factors that affect the quality of AIS including: (1) user involvement AIS; (2) Organizational structure. The external expert does not affect quality of AIS.

The multiple linear regression model is expressed as follows:

$$
A S Q=3.066+0.437 * U I N+0.452 * O S T
$$


Table 5. Result of regression analysis

\begin{tabular}{|c|c|c|c|c|c|c|c|}
\hline \multirow[b]{2}{*}{ Model } & \multicolumn{2}{|c|}{ Unstandardized Coefficients } & \multirow{2}{*}{$\begin{array}{c}\text { Standardized } \\
\text { Coefficients }\end{array}$} & \multirow[b]{2}{*}{$\mathrm{t}$} & \multirow[b]{2}{*}{ Sig. } & \multicolumn{2}{|c|}{ Collinearity Statistics } \\
\hline & B & Std. Error & & & & Tolerance & VIF \\
\hline Constant & 3.066 & 1.029 & & 2.980 & 0.003 & & \\
\hline UIN & .437 & 0.121 & .283 & 3.594 & 0.000 & 0.621 & 1.610 \\
\hline EXP & .120 & .095 & .095 & 1.261 & 0.209 & 0.687 & 1.456 \\
\hline OST & .452 & 117 & .308 & 3.865 & 0.000 & 0.609 & 1.643 \\
\hline
\end{tabular}

\section{CONCLUSIONS AND IMPLICATION FOR RESEARCH}

\subsection{Conclusions}

From the 3 factors derived from theoretical analysis and based on the results of previous studies in the world, the result of the study after perform in Vietnam found that there are two factors impact on the quality of AIS is: (1) user involvement AIS; (2) organizational structure. In addition, the research also found that the external expert did not have a significant impact on the quality of AIS.

\subsection{Implication for research}

The result of this study also have implications for enterprises to pay attention to and improve the quality of AIS as well as to consider the management factors in the operation AIS to help the managers have trust orientation for the development of AIS in the process of international economic integration. Recognizing the importance of AIS in increasing the value of the company and improving the quality of AIS is an important task in the competitive environment. Specifically, enterprises should focus on promoting the following issues.

Emphasizing the users involvement AIS, when they participate in the issues of AIS, they will understand how the system is working, thereby promoting the development system. The user involvement with the system will be an important factor to make the AIS more qualified by showing that employees are more dedicated and stick to the system they are using. Therefore, in relation to the issues of AIS during the analysis, design, implementation and operation AIS, there should be the user participation of the system. Managers need to be aware of this in all business activities because the element of user participation is an important factor for the success of AIS.

The organizational structure demonstrates the ability to manage and operate the business, the assignment of personnel, the clarification of the rights and responsibilities of employees in the process of work will affect the way the work of personnel. The organization staff is reasonable with position, function and level of staff will help to maximize the work capacity of employees. When employees are arranged, assign properly with their abilities, they will feel loved and responsible of completing the work well, thereby improving productivity and efficiency of work. Suitable organizational structure is considered an effective management method in business environment, helping accountants improve the quality of work and improve the quality of AIS.

Although the initial purpose was to assess the impact of factors on the quality of AIS, however, the research has some limitations:

Firstly, the author has just conducted a survey in Ho Chi Minh City, so the generality of the research is not high and can be limited. In addition, the study uses a convenient sampling technique by sending questionnaire directly. Consequently, further studies should be conducted in different areas so that a more comprehensive picture of the effect of factors on the quality of AIS can be seen. 
Second, this study was conducted over a short period of time due to time and budget constraints in conducting the study, so the sample size was not large.

Third, the level of interpretation of the independent variables for the dependent variable is not high, because there are many other factors that may affect the quality of AIS. Therefore, further studies should be conducted with a larger sample size and consideration of other factors that may affect the quality of AIS in the Vietnamese market.

\section{REFERENCES}

[1] Abelein, U., \& Paech, B. (2015). Understanding the influence of user participation and involvement on system success-A systematic mapping study. Empirical Software Engineering, 20(1), 28-81.

[2] Anggadini, S. D. (2013). The Accounting Information Quality And The Accounting Information System Quality Through The Organizational Structure : A Survey Of The Baitulmal Wattamwil (BMT) In West Java Indonesia. International Journal of Business and Management Invention, 2(10), 12-17.

[3] Attewell, P. (1992). Technology diffusion and organizational learning: The case of business computing. Organization science, 3(1), 1-19.

[4] Baroudi, J. J., Olson, M. H., \& Ives, B. (1986). An empirical study of the impact of user involvement on system usage and information satisfaction. Communications of the ACM, 29(3), 232-238.

[5] Carolina, Y. (2014). Organizational Factors and Accounting Information System Quality (Empiric Evidence From Manufacturing Firms in Bandung Indonesia). Research Journal of Finance and Accounting, 5(5), 192199.

[6] Davenport, T. H. (2000). Putting the enterprise into the enterprise system. Harvard business review, 76(4).

[7] Delone, W. H., \& McLean, E. R. (2003). The DeLone and McLean model of information systems success: a ten-year update. Journal of management information systems, 19(4), 9-30.

[8] Gable, G., Sedera, D., \& Chan, T. (2003). Enterprise systems success: a measurement model. ICIS 2003 Proceedings, 48.

[9] Gefen, D. (2004). What makes an ERP implementation relationship worthwhile: Linking trust mechanisms and ERP usefulness. Journal of Management Information Systems, 21(1), 263-288.

[10] Gelinas, U. J., Dull, R. B., \& Wheeler, P. (2011). Accounting information systems. Cengage learning.

[11] Greenberg, J. (2011). Behavior in organizations. Pearson

[12] Jones, G. R., \& Jones, G. R. (2010). Organizational theory, design, and change.

[13] Hair, J. F., Black, W.C., Babin, B.J., Anderson. RE \& Tatham, RL (2006). Multivariate data analysis.

[14] Hartwick, J., \& Barki, H. (1994). Explaining the role of user participation in information system use. Management science, 40(4), 440-465.

[15] Ifinedo, P. \& Sundberg, K. 2012. Influences of Organizational Objectives, Culture, and IT Support/Knowledge on ERP System Effectiveness: An Empirical Investigation. 9th International Conference on Enterprise Systems, Accounting and Logistics.

[16] Markus, M. L., \& Tanis, C. (2000). The enterprise systems experience-from adoption to success. Framing the domains of IT research: Glimpsing the future through the past, 173, 207-173. 
[17] McKeen, J.D., Guimaraes, T., and Wetherbe, J.C. (1994) The Relations Between User Participation and User Satisfaction: An Investigation of Four Contingency Factors, MIS Quarterly 18, 4, 427-451.

[18] Nunnally, J. C., \& Bernstein, I. H. (1994). Psychological theory. New York, NY: MacGraw-Hill.

[19] Nusa, I. B. S. (2015). Influence Of Organizational Culture And Structure On Quality Of Accounting Information System. INTERNATIONAL JOURNAL OF SCIENTIFIC \& TECHNOLOGY RESEARCH, 4(5), 257-267.

[20] Petter, S., DeLone, W., \& McLean, E. (2008). Measuring information systems success: models, dimensions, measures, and interrelationships. European journal of information systems, 17(3), 236-263.

[21] Robbins, S. P., \& Judge, T. A. Organizational Behavior (2009).

[22] Robbins, S. P., \& Coulter, M. (2009). Management (the 10th Edition).

[23] Rapina. (2014). Factors Influencing The Quality of Accounting Information System And Its Implications on The Quality of Accounting Information. Research Journal of Finance and Accounting, 5(2), 148-154.

[24] Sačer, I. M., Žager, K., \& Tušek, B. (2006, January). Accounting information system's quality as the ground for quality business reporting. In IADIS International conference, e-commerce 2006.

[25] Sajady, H., Dastgir, M., \& Nejad, H. H. (2008). Evaluation of the effectiveness of accounting information systems. International journal of information science and technology, 6(2).

[26] Seddon, P. B. (1997). A respecification and extension of the DeLone and McLean model of IS success. Information systems research, 8(3), 240-253.

[27] Sedera, D., Gable, G., \& Chan, T. (2004). Measuring enterprise systems success: the importance of a multiple stakeholder perspective. ECIS 2004 Proceedings, 100.

[28] Soudani, S. N. (2012). The usefulness of an accounting information system for effective organizational performance. International Journal of Economics and Finance, 4(5), 136.

[29] Stair, R. M., \& Reynolds, G. W. (2010). Principles Of Information Systems, Course Technology. 9th Editions. NY: Mc-Graw-Hill.

[30] Susanto, A. (2013). Accounting Information Systems: Development of Risk Control Structure. Prime Edition. First mold. Bandung: Lingga Jaya.

[31] Thong, J. Y., Yap, C. S., \& Raman, K. S. (1996). Top management support, external expertise and information systems implementation in small businesses. Information systems research, 7(2), 248-267.

[32] Wang, E.T.G \& Chen, J.H.F. (2006). Effects of internal support and consultant quality on the consulting process and ERP system quality, Decision Support System, Vol. 42, No. 2, pp. 1029-1041.

Received on February 1st, 2019

Accepted on March 25th, 2019

(C) 2019 Industrial University of Ho Chi Minh City 